\title{
The Impact of Preserving Pelvic Perfusion Using Iliac Branch Devices on Quality of Life
}

\author{
Chinai ${ }^{1 *}$, Papworth $E^{1}$, Balasubramaniam K², Coulston JE', Eyers PS ${ }^{1}$, Ward T², Stewart AHR ${ }^{1}$ and Hunter ID ${ }^{1}$
}

${ }^{1}$ Department of Vascular Surgery, Taunton and Somerset NHS Foundation Trust, Taunton, UK

${ }^{2}$ Department of Interventional Radiology, Taunton and Somerset NHS Foundation Trust, Taunton, UK

\begin{abstract}
Background: Aorto-iliac aneurysms with extensive iliac involvement compromise distal seal during endovascular repair. Sacrificing internal iliac artery, with embolization, and therefore pelvic perfusion to create an adequate distal landing zone is associated with significant morbidity. The aim of this study was to compare patient related outcomes and quality of life between preserving pelvic perfusion with iliac branch devices and embolization.

Methods: Patients undergoing elective infrarenal EVAR with internal iliac adjunct over a 4-year period were identified from prospective local and national databases. Case notes and procedural images were reviewed. Patients were contacted by telephone to assess post-operative symptoms and impact on quality of life using validated questionnaires.

Results: 12 patients had iliac branch devices (IBD) implanted and 16 patient's internal iliac artery embolization. IBD technical success rate was $92 \%$ with $100 \%$ patency rate at median follow-up of 12 months. Higher morbidity was associated with loss of pelvic perfusion and patients reported poorer quality of life. 4 patients developed new erectile dysfunction in the embolization group (0 IBD; $p=0.06)$. New ipsilateral buttock claudication developed in 1 patient with preserved IIA perfusion by IBD and 8 with occluded IIA $(p=0.03)$.

Conclusions: Routine embolization of IIA to treat aortoiliac aneurysms results in significant morbidity and reduces patient reported quality of life. Preservation of pelvic perfusion with successful IBD implantation may reduce postoperative ipsilateral buttock claudication and thus have a positive impact on quality of life. Larger prospective patient reported outcome measure studies after endovascular aneurysm repair are required alongside safety and efficacy trials.
\end{abstract}

Keywords: Quality of life; Aortoiliac aneurysm; Pelvic perfusion; Buttock claudication; Iliac branch device

\section{Introduction}

Since the first description of endovascular aortic aneurysm repair (EVAR) by Parodi in 1991 the technology and experience has matured, which in turn has revolutionized the treatment of aortic aneurysms. Prospective randomized studies have shown that EVAR significantly reduces blood loss, operative times, length of stay, morbidity and perioperative mortality when compared to traditional open repair [1-3]. However, the applicability has been limited by extension of aneurysmal disease into the iliac arteries. While isolated iliac artery aneurysms $(0.03 \%$ in the general population) are rare, ectatic or aneurysmal iliac arteries may be present in up to $30 \%$ of patients referred for standard EVAR $[4,5]$.

Dilatation of one or both common iliac arteries (CIA) compromises the success of endovascular repair due to inadequate distal sealing. Traditionally this has been dealt with by embolizing one or both internal iliac arteries (IIA) and extension of the stent graft to the external iliac artery (EIA). However, the sacrifice of the IIA, especially bilateral, is not as innocuous as initially reported. Up to a third of patients will develop severe buttock claudication, which may improve over time, but persists in up to $15 \%$ of patients [6-8]. $17 \%$ of patients develop new onset erectile dysfunction [8] and less frequently complications of IIA occlusion include bowel or spinal ischemia and necrosis of the scrotal skin. Buttock claudication and erectile dysfunction can significantly impair quality of life (QoL) [7,8]. These individuals are not only limited in their walking capacity and levels of physical activity but also demonstrate a decline in other QoL domains such as social and emotional well-being [9].
Recently branched stent grafts for preservation of the IIA have been described with encouraging results [10-18]. The iliac branch device (IBD) extends from a conventional EVAR stent-graft in to the EIA whilst preserving flow in to the ipsilateral IIA using a side branch. Preserving at least one IIA is believed to allow adequate pelvic perfusion and reduce the frequency of complications and disability.

The aim of this study was to evaluate the patient-related clinical benefit on morbidity and quality of life when compared to the conventional practice of embolizing the internal iliac artery. We also describe our unit's experience with iliac branch device technique.

\section{Methods}

All consecutive patients undergoing elective endovascular treatment for an infra-renal aneurysm between January 2008 and December 2012 were reviewed. Prospectively collected data for aneurysms involving the iliac bifurcation were retrospectively analyzed. Patients with a CIA

*Corresponding author: Chinai N, Department of Vascular Surgery, Taunton and Somerset NHS Foundation Trust, Taunton, UK, Tel: +441823333444; E-mail: natashachinai@nhs.net

Received September 20, 2017; Accepted October 06, 2017; Published October 17, 2017

Citation: Chinai N, Papworth E, Balasubramaniam K, Coulston JE, Eyers PS, et al. (2017) The Impact of Preserving Pelvic Perfusion Using Iliac Branch Devices on Quality of Life. J Vasc Med Surg 5: 344. doi: 10.4172/2329-6925.1000344

Copyright: ( 2017 Chinai N, et al. This is an open-access article distributed under the terms of the Creative Commons Attribution License, which permits unrestricted use, distribution, and reproduction in any medium, provided the original author and source are credited. 
diameter $>25 \mathrm{~mm}$ were considered for treatment with an IBD based on the following criteria:

- Non-aneurysmal distal landing zone in the EIA with a length $\geq$ $22 \mathrm{~mm}$ and diameter $\geq 8 \mathrm{~mm}$ but less than $11 \mathrm{~mm}$.

- Non-aneurysmal internal iliac artery segment $\geq 10 \mathrm{~mm}$ in length and $\leq 10 \mathrm{~mm}$ in diameter (outer to outer) distal to the aneurysm segment

- Iliac morphology (tortuosity, stenosis and/or calcification) that did not preclude delivery of the device.

In cases of bilateral iliac aneurysms the anatomically more favourable side was treated with an iliac branch device while the contralateral side was treated with embolization of the IIA and extension of the aortoiliac stent to the external iliac artery.

All patients treated with an IBD received a Zenith bifurcated iliacbranch device (COOK Inc., Bloomington, IN) with a covered bridging stent (Advanta V12, Atrium Medical, Hudson, NH, USA). Embolization of the internal iliac artery was performed using Amplatzer ${ }^{\mathrm{ma}}$ plugs, platinum coils or a combination of the two. These were placed in the main trunk or first branch of the IIA to reduce the risk of pelvic ischemia.

Our institution's ethical guidelines and research governance framework were consulted. As the study did not in any way influence patient management it was exempt from requiring formal ethical approval. All patients participating in the patient reported outcomes gave informed consent to do so.

\section{Outcome measures}

Primary outcomes were morbidity, specifically pelvic ischemia (new ipsilateral buttock or thigh claudication and new erectile dysfunction) and claudication specific as well as generic health-related quality of life after EVAR.'New buttock claudication' was defined as claudication symptoms that had developed within the first 6-weeks following treatment and were still present at 6 months. Demographic and clinical data including age, sex, co-morbidities, smoking history and preprocedure claudication history were collected from the prospective database and patient case notes. Quality of life data were collected using patient delivered questionnaires:

- Walking Impairment Questionnaire (WIQ): A valid tool that detects a change in daily walking ability of patients with intermittent claudication. In the WIQ distance score the degree of difficulty in walking specified distances is assessed. In the WIQ speed score the degree of difficulty in waking one block at specified speeds is assessed and in the WIQ stair-climbing score the degree of difficulty climbing specific numbers of flights of stairs is recorded. All domains are recorded on a graded scale from 0 to 4 . The graded score are then multiplied by a prespecified weight for each distance, speed or number of flights of stairs and the products summed and divided by the maximum possible score to obtain a percent score ranging from 0 (inability to perform task) to 100 (no difficulty with any tasks) $[19,20]$.

- The Short-Form 12 (SF-12): A validated questionnaire that measures general health and vitality across eight domains: physical functioning; role limitations due to physical health; role limitations due to emotional problems; energy/fatigue; emotional well-being; social functioning; pain; general health. Health related quality of life summary scores are then derived from these eight domains with higher scores indicating higher levels of health $[21,22]$.

- EuroQoL five dimensions (EQ-5D) Questionnaire: A twopart descriptive tool that assesses generic health status. In the first part respondents describe their health by checking one level of severity (none, slight, moderate, severe, extreme/unable to) on five dimensions (mobility, self-care, usual activities, pain/discomfort, anxiety/depression). In the second part, the respondents indicate how good or bad their overall health is on a visual scale (0-100). We analyzed health status reporting on the descriptive profile, EQ-5D Index and EQ-VAS [23,24].

Secondary outcome measures were technical success, defined as successful implantation of the IBD with preservation of antegrade flow to the pelvis; and IBD patency.

\section{Statistical analysis}

All data were analyzed on an intention to treat basis using Microsoft Excel 2007. Statistical analysis was performed using the $\mathrm{X}^{2}$ test for categorical variables. Continuous data was analysed using the Student's t-test for normally distributed data and the Mann-Whitney $\mathrm{U}$ test for non-parametric data. Univariate logistic regression analysis was performed to assess if age was an independent predictor of buttock claudication and a decline in quality of life scores. Statistical significance was set a $\mathrm{p}<0.05$ for all tests.

\section{Results}

From January 2008 to December 2012, 237 endovascular procedures were performed to treat infra-renal abdominal aortic aneurysms (AAA). During this time twenty-eight adjunct procedures were required due to aneurysmal aorto-iliac disease. There were no significant differences in the demographic characteristics between patients in the IBD group and embolization group, except for age. Twelve patients, mean age 71.5 \pm 7.2 years, were treated with an iliac branch device and 16 patients (mean age $80.1 \pm 6.2$ years) had internal iliac artery embolization. Four patients died since their EVAR (non-aneurysmal related deaths; 2 from each group) and were excluded from any further analysis. Eight patients (33\%) had documented pre-treatment erectile dysfunction. Only two patients $(8 \%)$ had documented pre-treatment buttock claudication. The baseline characteristics of patients in each group are summarized in Table 1. All patients that were alive during the retrospective review period $(n=24)$ completed the three questionnaires.

The immediate technical success rate for IBD implantation was $92 \%(n=11)$. In one patient there was retrograde stent migration with consequent failure to connect the iliac branch with the internal iliac artery resulting in partial deployment of the stent. Subsequently a decision was made to embolize the left IIA during the procedure and extend the stent graft into the external iliac artery as for conventional EVAR following embolization. The median follow-up period is 12 months (range 6-60) with a 100\% iliac branch device patency. There was 1 Type II endoleak in the IBD group at 1 month, which had completely resolved without intervention at 36 months.

Overall, $10(42 \%)$ patients developed new persistent buttock claudication. Only 1 patient developed new ipsilateral buttock claudication, with a patent iliac device, in the IBD group and 7 patients developed new ipsilateral buttock claudication in the IIA embolization group $(\mathrm{p}=0.03)$. Four patients developed new post-treatment erectile dysfunction all of who were in the IIA embolization group $(\mathrm{p}=0.06)$. 
Citation: Chinai N, Papworth E, Balasubramaniam K, Coulston JE, Eyers PS, et al. (2017) The Impact of Preserving Pelvic Perfusion Using lliac Branch Devices on Quality of Life. J Vasc Med Surg 5: 344. doi: 10.4172/2329-6925.1000344

Page 3 of 5

\begin{tabular}{|c|c|c|c|}
\hline Characteristics & IBD & IIA embolization & p \\
\cline { 2 - 4 } & $\mathbf{( n = 1 2 )}$ & $\mathbf{( n = 1 6 )}$ & \\
\hline Age & $71.5 \pm 7.2$ & $80.1 \pm 6.2$ & $<0.05$ \\
\hline Male & 12 & 15 & - \\
\hline Current smokers & 1 & 2 & NS \\
\hline Hypertension & 2 & 5 & NS \\
\hline Diabetes & 1 & 1 & NS \\
\hline Hypercholestrolaemia & 1 & 1 & NS \\
\hline Ischemic Heart Disease & 0 & 3 & NS \\
\hline Stroke or TIA & 1 & 3 & $N S$ \\
\hline COPD & 1 & 2 & $N S$ \\
\hline Pre-treatment & & & $N S$ \\
\hline - Erectile dysfunction & 3 & 5 & $N S$ \\
\hline - Buttock Claudication & 1 & 1 & \\
\hline
\end{tabular}

\begin{tabular}{|c|c|c|c|c|c|c|}
\hline & \multicolumn{2}{|c|}{ PCS } & p & \multicolumn{2}{c|}{ MCS } & p \\
\hline & IBD & Embolization & & IBD & Embolization & \\
\hline Median & 43.2 & 35.2 & 0.09 & 56.7 & 52.5 & 0.4 \\
\hline IQR & $(25.8-50.9)$ & $(22.3-43.2)$ & & $(55.4-65.9)$ & $(46.9-58.2)$ & \\
\hline Maximum & 55.3 & 50.1 & & 66.1 & 69.1 & \\
\hline Minimum & 18.6 & 19.3 & & 54.1 & 30.6 & \\
\hline
\end{tabular}

PCS: Physical Component Summary; MCS: Mental Component Summary; IQR: Interquartile Range

Table 2: Comparison of physical and mental component summary scores between the IBD and embolization groups.

\section{Percentage of patients reporting a problem}

NS: Not significant.

Table 1: Demographic and clinical characteristics.

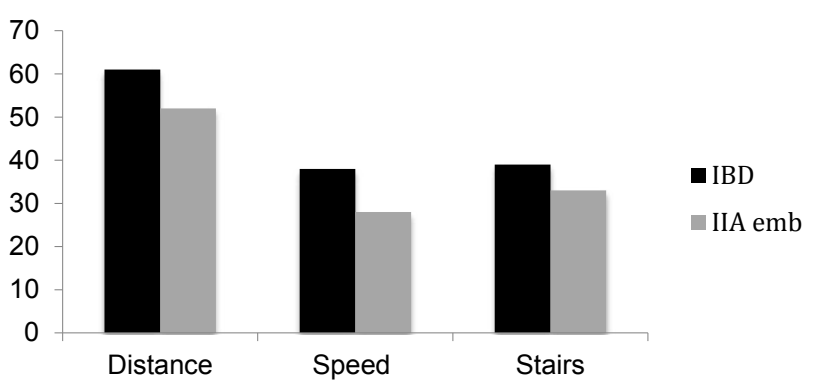

Figure 1: Walking Impairment Questionnaire: Mean scores between the groups for distance, speed and stairs.

\section{Walking impairment questionnaire}

Overall the patients in the IBD group had higher WIQ distance, speed and stair-climbing scores than patients in the IIA embolization group (mean scores: distance $61.4 \pm 39.5$ v $51.8 \pm 38.8 \mathrm{p}=0.6$; speed $37.6 \pm 28.1$ v $27.9 \pm 17.9 \mathrm{p}=0.3$; stair climbing $39.3 \pm 35.5$ v $32.7 \pm 25.1$ $\mathrm{p}=0.7$ ) (Figure 1).

\section{SF-12 questionnaire}

Table 2 shows the median summary scores for the SF-12 questionnaire for each treatment group. The patients in the IBD group had a higher physical and mental score when compared to the embolization group, indicating higher health states, although this did not achieve statistical significance.

\section{EQ-5D}

In all dimensions the proportion of patients reporting 'no problems' was higher in the IBD group. $36 \%$ of patients in the embolization group reported 'severe' problems with mobility and $22 \%$ with the ability to perform usual activities versus 0 in the IBD group. This was further supported with pain and discomfort scores, with $64 \%$ of patients in the embolization group reporting 'moderate' to 'severe' scores (Figure 2). The EQ5D Index scores were higher overall in the IBD group and this was statistically significant $(\mathrm{p}=0.01$ ) (Figure 3 ). Similarly the VAS scores were higher for the IBD group (mean $76 \pm 11 \vee 69 \pm 13 \mathrm{p}=0.11$ ) but this did not reach statistical significance.

\section{Influence of age}

Univariate regression analysis demonstrated that age was not an independent predictor of developing new ipsilateral buttock

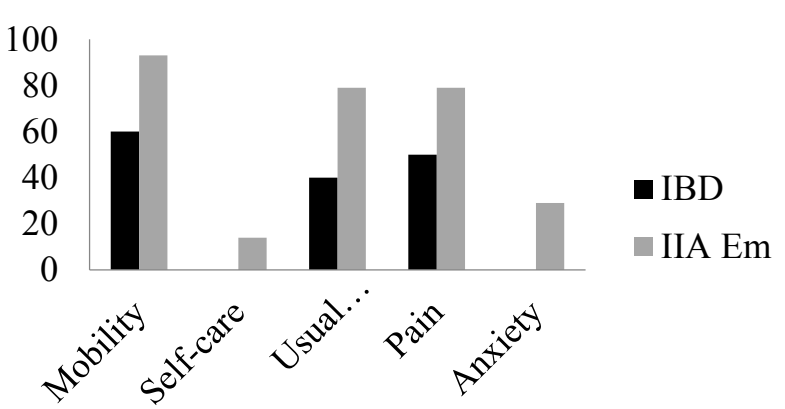

Figure 2: Scores above Level 2 on all domains on the EQ-5D questionnaire.

EQ5D-5L index values for IBD and Embolization

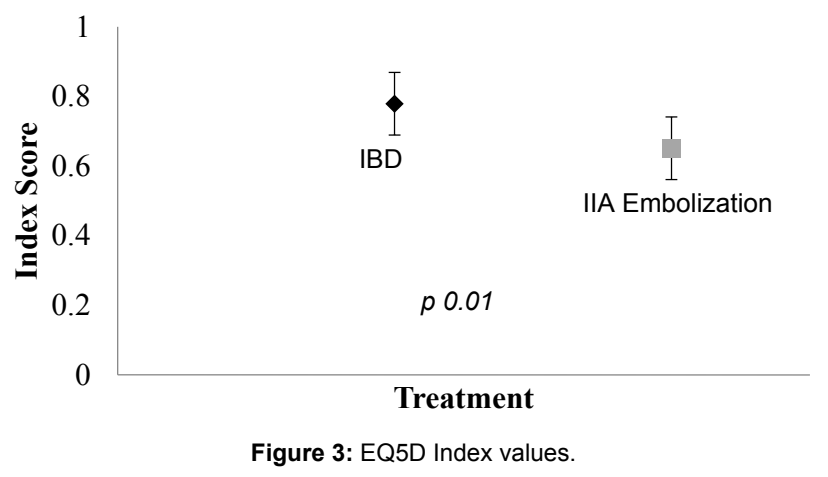

claudication $(\mathrm{p}=0.3)$. Furthermore, age alone was not associated with the decline in quality of life health scores on the SF-12 and EQ-5D questionnaires $(\mathrm{p}=0.3$ and $\mathrm{p}=0.5$ for the two SF- 12 domains respectively and $\mathrm{p}=0.3$ ).

\section{Discussion}

Currently there is no consensus on the management of aortoiliac aneurysms. The default treatment modality is embolization of the internal iliac artery with extension of the endograft into the external iliac artery. The literature reports buttock claudication occurs in 31$35 \%$ of IIA embolizations [8], and this was demonstrated in our study with $36 \%$ of patients developing buttock claudication after single IIA embolization.

These persistent symptoms have a significant impact on the quality of life (QoL) of patients, and QoL is increasingly considered an important outcome after all surgery. As far as we are aware there have been no 
studies that have quantified QoL after internal iliac artery embolization as an adjunct to EVAR. We observed that those patients that had a lower distance score on the walking impairment questionnaire and higher mobility scores on the EQ-5D, indicating limited pain-free walking, reported poorer overall health status. As with patients who present with calf claudication, those who develop buttock claudication may avoid activities that precipitate symptoms. This in turn may lead to decreased functional status, depression and as a result report poorer health states on quality of life questionnaires [25-27].

From population studies we know the prevalence of symptomatic claudication (calf and buttock) is $15-20 \%$ in individuals over 60 years $[28,29]$. Similarly the prevalence of erectile dysfunction increases with age and is $15 \%$ men over 60 [30]. The morbidity associated with IIA embolization in our series cannot be explained by age alone. Regression analysis did not demonstrate a statistically significant influence of age on the development of new ipsilateral buttock claudication or a decline in health-related quality of life scores.

Iliac branch device implantation, to preserve pelvic perfusion, has been shown in the literature to be safe $(>90 \%$ technical success rates with primary patency rates between $74-100 \%$ ) and our study supports this view.

The limitations of our study include data are based on a single centre experience with small numbers from a heterogenous population. Furthermore, this was a retrospective study and therefore we did not deliver pre-procedure quality of life questionnaires. Baseline data regarding buttock claudication and erectile dysfunction was collected from patient notes. Patient recall of pre-operative symptoms during the interviews was avoided to reduce bias.

This study and others have demonstrated the use of iliac branch devices is technically feasible and safe in maintaining pelvic perfusion via the internal iliac artery, as well as the benefits of revascularization with IBD in buttock claudication. But the possible effects on quality of life have not been considered previously. Decline in mobility and self-care is of critical importance in patients. Our study is the first to consider patient related outcomes following IBD deployment. Within the limitations of this study we have demonstrated a positive effect on quality of life and consider preserving at least one internal iliac artery in all patients with favorable anatomy irrespective of age or lifestyle.

The World Health Organization defines health as a state of physical, social and mental well-being [31]. Quality of life as an outcome measure after vascular surgery has become increasingly important because a significant proportion of interventions aim to improve not only quantity of life but quality as well. Larger prospective studies to assess quality of life before and after EVAR with adjunctive procedures are required.

\section{References}

1. Matsumura JS, Brewster DC, Makaroun MS, Naftel DC (2003) A multicenter controlled clinical trial of open versus endovascular treatment of abdominal aortic aneurysm. J Vasc Surg 37: 262-271.

2. Lee WA, Carter JW, Upchurch G, Seeger JM, Huber TS (2004) Perioperative outcomes after open and endovascular repair of intact abdominal aortic aneurysms in the United States during 2001. J Vasc Surg 39: 491-496.

3. Prinssen M, Verhoeven ELG, Buth J, Cuypers PWM, Van Sambeek MRHM et al. (2004) A Randomized Trial Comparing Conventional and Endovascular Repair of Abdominal Aortic Aneurysms. NEJM 351: 1607-1618.

4. Brunkwall J, Hauksson $H$, Bengtsson $H$, Bergqvist $D$, Takolander R, et al (1989) Solitary aneurysms of the iliac arterial system: an estimate of their frequency of occurrence. J Vasc Surg 10: 381-384.
5. Karthikesalingam A, Hinchcliffe RJ, Holt PJE, Boyle JR, Loftus IM, et al. (2010) Endovascular aneurysm repair with preservation of the internal iliac artery using the iliac branch device. Eur J Vasc Endovasc Surg 39: 285-294.

6. Mehta M, Veith FJ, Ohki T, Cynamon J, Goldstein K, et al. (2001) Unilateral and bilateral hypogastric artery interruption during aortoiliac aneurysm repair in 154 patients: a relatively innocuous procedure. J Vasc Surg 33: 27-32.

7. Karch LA, Hodgson KJ, Mattos MA, Bohannon WT, Ramsey DE, et al. (2000) Adverse consequences of internal iliac artery occlusion during endovascular repair of abdominal aortic anerysms. J Vasc Surg 32: 676-683.

8. Rayt HS, Bown MJ, Lambert KV, Fishwick NG, McCarthy MJ, et al. (2008) Buttock claudication and erectile dysfunction after internal iliac artery embolization in patients prior to endovascular aortic aneurysm repair. Cardiovasc Intervent Radiol 31: 728-734.

9. Khaira HS, Hanger R, Shearman CP (1996) Quality of life in patients with intermittent claudication. Eur J Vasc Endovasc Surg 11: 65-69.

10. Dias NV, Resch TA, Sonesson B, Ivancev K, Malina M (2008) EVAR of aortoiliac aneurysms with branched stent-grafts. Eur J Vas Endovasc Surg 35: 677-684.

11. Serracino-Inglott $F$, Bray AE, Myers $P$ (2007) Endovascular abdominal aortic aneurysm repair in patients with common iliac artery aneurysms - Initia experience with the Zenith bifurcated iliac side branch device. J Vasc Surg 46: $211-217$

12. Ziegler P, Avgerinos ED, Umscheid T, Perdikides T, Erz K, et al. (2007) Branched iliac bifurcation: 6 years experience with endovascular preservation of internal iliac artery flow. J Vasc Surg 46: 204-210.

13. Haulon S, Greenberg RK, Pfaff K, Francis C, Koussa M, et al. (2007) Branched grafting for aortoiliac aneurysms. Eur J Vas Endovasc Surg 33: 567-574.

14. Parlani G, Verzini F, Rango PDe, Brambilla D, Coscarella C, et al. (2012) Longterm results of iliac aneurysm repair with iliac branched endograft: A 5-year experience on 100 consecutive cases. Eur J Vas Endovasc Surg 43: 287-292.

15. Austermann M, Bisdas T, Torsello G, Bosiers M, Lazaridis K, et al. (2013) Outcomes of a novel technique of endovascular repair of aneurismal internal iliac arteries using iliac branch devices. J Vasc Surg 58: 1186-1191.

16. Maurel B, Bartoli M, Jean-Baptiste E, Reix T, Cardon A, et al. (2013) Perioperative evaluation of iliac ZBIS branch devices: A French multicente study. Ann Vasc Surg 27: 131-138.

17. Fernandez-Alonso L, Fernandez-Alonso S, Grijalba FU, Fariña ES, Aguilar EM et al. (2013) Endovascular treatment of abdominal aortic aneurysms involving iliac bifurcation: Role of iliac branch graft device in prevention of buttock claudication. Ann Vasc Surg 27: 851-855.

18. Pratesi G, Fargion, Pulli R, Barbante M, Dorigo W, et al. (2013) Endovascular treatment of aorto-iliac aneurysms: Four-year results of iliac branch endograft. Eur J Vas Endovasc Surg 45: 607-609.

19. Regensteiner JG, Steiner JF, Hiatt WR (1996) Exercise training improves functional status in patients with peripheral arterial disease. J Vasc Surg 23 104-115.

20. Jain A, Liu K, Ferrucci L, Criqui MH, Tian L, et al. (2012) The Walking Impairment Questionnaire stair-climbing score predicts mortality in men and women with peripheral arterial disease. J Vasc Surg 55: 1662-1673.

21. Ware JE, Kosinski M, Keller SD (1995) SF-12: How to score the SF-12 physical and mental health summary scales, ( $2^{\text {nd }}$ edn.), The Health Institute, New England Medical Centre.

22. Melville MR, Lari MA, Brown N, Young T, Gray D (2003) Quality of life assessment using the short form 12 questionnaire is as reliable and sensitive as the short form 36 in distinguishing symptom severity in myocardial infarction survivors. Heart 89: 1445-1446.

23. Feng $Y$, Devlin N, Herdman M (2015) Assessing the health of the genera population in England: how do the three- and five-level versions of EQ-5D compare? Health and Quality of Life Outcomes 13: 171-187.

24. Herdman M, Gudex C, Lloyd A, Janssen MF, Kind P, et al. (2011) Development and preliminary testing of the new five-level version of EQ-5D (EQ-5D-5L) Quality of Life Research 20: 1727-1736.

25. Wattanakit K, Williams JE, Schreiner PJ, Hirsch AT, Folsom AR (2005) Association of anger proneness, depression and low social support with peripheral arterial disease: the Atherosclerosis Risk in Communities Study. Vasc Med 10: 199-206. 
Citation: Chinai N, Papworth E, Balasubramaniam K, Coulston JE, Eyers PS, et al. (2017) The Impact of Preserving Pelvic Perfusion Using lliac Branch Devices on Quality of Life. J Vasc Med Surg 5: 344. doi: 10.4172/2329-6925.1000344

Page 5 of 5

26. Chetter IC, Spark JI, Dolan P, Scott DJA, Kester RC (1997) Quality of life analysis in patients with lower limb ischaemia: Suggestions for European standardization. Eur J Vas Endovasc Surg 13: 597-604

27. Mays RJ, Casserly IP, Kohrt WM, Ho PM, Hiatt WR, et al. (2011) Assessment of Functional Status and Quality of Life in Claudication. J Vasc Surg 53: 14101421.

28. Criqui MH, Aboyans V (2015) Epidemiology of Peripheral Artery Disease. Circulation Research 116: 1509-1526.
29. Fowkes FG, Rudan D, Rudan I, Aboyans V Denenberg JO, et al. (2013) Comparison of global estimates of prevalence and risk factors for peripheral artery disease in 2000 and 2010: a systematic review and analysis. Lancet 382: $1329-1340$

30. Feldman HA, Goldstein I, Hatzichristou DG, Krane RJ, McKinlay JB (1994) Impotence and its medical and psychosocial correlates: Results of the Massachusetts Male Aging Study. J Urol 151: 54-61.

31. World Health Organisation (1947) The constitution of the WHO. WHO Chronicle 1: 29. 